\title{
HPTLC fingerprinting of various extracts of Couroupita guianensis flowers for establishment of in vitro antimalarial activity through isolated compound
}

\author{
R. Shwetha , T. S. Roopashree, Kuntal Das*, N. Prashanth and Rakesh Kumar \\ Department of Pharmacognosy, Government College of Pharmacy, Bengaluru-560027, Karnataka, India \\ *Department of Pharmacognosy and Natural Product Chemistry, Krupanidhi College of Pharmacy, \#12/1, Chikkabellandur, Carmelaram Post, \\ Varthur Hobli, Bangaluru-500035, Karnataka, India
}

\section{Article Info}

Article history

Received 13 April 2020

Revised 1 June 2020

Accepted 3 June 2020

Published online 30 June 2020

Keywords

Couroupita guianensis Aubl.

anti-malarial

$\beta$ hematin

HPTLC

\begin{abstract}
Malaria is the most common infectious disease, due to multi drug resistance parasites and the limited number of effective drugs available in this situation is complicated, it is necessary to discover new antimalarial drugs. HPTLC fingerprint analysis is the most potent tool for quality control and standardization of herbal drugs. In the present study, five different extracts of Couroupita guianensis Aubl. flowers were screened for their anti-malarial activity by in vitro inhibition of $\beta$ hematin formation assay and their HPTLC fingerprinting was carried out. The most potent antimalarial activity was shown by ethyl acetate extract of flowers then isolation of compound responsible for activity was carried out and characterized by UV, FTIR, H-NMR, Mass Spectroscopy, the structure was found to be Stigmasterol.
\end{abstract}

\section{Introduction}

Malaria is a fatal tropical disease, causes by a genus Plasmodium (Protozoa). It is a parasite named Plasmodium falciparum, affect humans by far the most virulent. As per WHO, the estimated death rate due to malaria was 405000 in the year 2018 and still the death is occurs globally in several countries (WHO, 2019). There are many synthetic medicines applied for the treatment of malaria but are having many side effects and also shows resistance. Therefore, it is a serious challenge due to the emergence of $P$. falciparum strains resistant to all antimalarial drugs. To overcome the challenge, medicinal plants have played an important role in malaria treatment with their new chemical compounds. It was reported that two major drugs, quinine and artemisinin that are used worldwide, herbal based compounds. Hence, many developing countries are depending on medicinal plants to meet their primary health care needs (WHO, 2010).

Of late, Couroupita guianensis Aubl. (CG) commonly called as cannon ball tree, belongs to the angiosperm family Lecythidaceae. This plant has enormous therapeutical uses. In Indian system of medicine, it is used as an ingredient in many preparations to cure gastritis, bleeding piles, dysentery, scabies and many other conditions (Shah et al., 2012; Manimegalai et al., 2014). More than 30 species are recognised for genus Couroupita throughout the world. It is native to South India and Malaysia. Cannon ball flowers (Nagalingam flowers) are announced as the State flower by Puducherry Government (Ramalakshmi et al., 2014; Chavda, 2015).

Corresponding author: Ms. R. Shwetha

Department of Pharmacognosy, Government College of Pharmacy, Bengaluru-560027, Karnataka, India

E-mail: shwetharamesh641@gmail.com

Tel.: +91-9019222658

Copyright (C) 2020 Ukaaz Publications. All rights reserved.

Email: ukaaz@yahoo.com; Website: www.ukaazpublications.com
Characteristics of the plant: $\mathrm{CG}$ is a large deciduous tree with height up to 20 meters. Leaves are up to $20 \mathrm{~cm}$ long, serrate margin, arranged alternate with oblong to obovate shape. It shows large branches with racemose inflorescence. Flowers are zygomorphic with high fragrance. Flowers are up to $6 \mathrm{~cm}$ in diameter with six petals, colour ranges from shades of pink and red with yellow tinge. Stamens are at two areas; a ring of stamens at the centre and stamens borne on an overarching androphore. Fruits are large globose with woody shell hangs in cluster like balls hanging in a string. The fruits have unpleasant smelling edible jelly and small 200-300 white seeds embedded in pulp. Pulp oxidizes to bluish green colour when exposed to air. The hard woody shells of the fruits are used to prepare containers and utensils (Regina, 2014; Aravind et al., 2017; Ramadoss, 2017). Because of its attractive flowers and fragrance, it is grown as a decorative tree in Indian gardens. It is called in different names in different languages like Kailaspati in Hindi, Mallikarjuna flowers in Telugu, Nagalingam flowers in Tamil.

Ethnic uses: In India usually, these trees are planted near Shiva temple and used for Shiva pooja because of its Shivalingam shape present at the centre of the flower and like snake hood designed pollens (Sundararajan and Koduru, 2014). Leaves of CG are used in the treatment of skin diseases (Sumathi and Anuradha, 2017). Leaves and flowers are used in the treatment of cold, enteric gas formation and abdomen ache (Elumalai et al., 2012; Sundararajan and Koduru, 2014). The flower of CG is evident of analgesic, anti-inflammatory, immunomodulatory, anthelmintic, antimicrobial, wound healing, antioxidant and antinociceptive activities (Geetha et al., 2005; Umachigi et al., 2007; Pradhan et al., 2008; Bhagyasri et al., 2014).

Phytochemistry: Phytochemical screening showed the presence of alkaloids, flavonoids, sterols, glycosides, tannins, triterpenes, isatin, indirubin, couroupitine, $\alpha$-amirin, $\beta$-amirin in the leaves and flowers 
(Rane et al., 2001; Eknat and Shivchandraji, 2002; Gousia et al., 2013) and the various therapeutic activities are observed due to the presence of these essential phytoconstituents. The leaves and fruits of CG tree are used to treat malaria by South Americans (Sathishkumar et al., 2016; Jasmine and Moorthi, 2017; Sumathi and Anuradha, 2017). Leaves of CG showed good antiplasmodial activity (Kaushik et al., 2015) whereas traditionally flower is effective against high fever, abdominal pain, diarrhoea, dysentery, and acts as immune booster (Ramalakshmi et al., 2013; Prabhu and Ravi, 2017; Lawrence and Venkatraman, 2020). The symptoms of antimalarial activity and the traditional applications of flowers are quite similar and even there is no scientific evidence for antimalarial activity of CG flowers. Therefore, it was essential to investigate the antimalarial activity of CG flowers and to isolate the compound responsible for the same.

\section{Materials and Methods}

\subsection{Materials}

Fresh flowers of CG were collected from T. Dasarahalli, Bengaluru. Identification and authentication of plant material was done by Dr. Rama Rao at Regional Ayurveda Research Institute, Bengaluru. The authentication reference number bears SMPU/RARIMD/BNG/ 2018-19/1580.

\subsection{Methods}

\subsubsection{Extraction of crude drugs}

Fresh flowers were collected from Bengaluru during the month of June, cut into small pieces and shade dried for 7-8 days then ground into a coarse powder, sieved using sieve \#12.

Dried and powdered flowers of CG $(50 \mathrm{~g})$ were extracted by packing into a thimble and extracted in Soxhlet apparatus successively with solvents of increasing polarity, viz., pet-ether, chloroform, ethyl acetate, ethanol, methanol, and water until the siphon tube was colourless. Before extracting with the next solvent, marc was pressed to remove the residual solvent. The extract obtained was filtered and concentrated to dryness. The percentage yield was calculated in terms of air-dried weight of plant material and dried extracts were stored in airtight glass container for further phytochemical screening and antimalarial study.

\subsubsection{HPTLC fingerprinting}

2.2.2.1 Sample preparation: All extracts were re-dissolved in $1 \mathrm{ml}$ of respective solvents

2.2.2.2 Application of sample: Samples were applied on pre-coated silica gel $60 \mathrm{~F} 254$ aluminium sheets $(10 \times 10 \mathrm{~cm})$ with the help of Linomat 5 applicator attached to the CAMAG HPTLC system, which was programmed through WINCATS software. The application of bands of each extract was carried out $6 \mathrm{~mm}$ band in length and $2 \mu 1$ in concentration.

2.2.2.3 Developing solvent system: A number of solvent systems were tried for flowers and fruits extract, but the satisfactory resolution was obtained in the solvent system Toluene: Ethyl acetate: Formic acid: Methanol (5.5:3:1:0.5) for flowers extracts.

2.2.2.4 Development of chromatogram: After the application of the sample, the chromatogram was developed in Twin trough glass chamber $20 \times 10 \mathrm{~cm}$ with solvent system Toluene: Ethyl acetate: Formic acid: Methanol (5.5:3:1:0.5) for flower extracts.
2.2.2.5 Detection of spots: The air-dried plates were placed in the TLC scanner at position 0 (right hand side). The first track spotted should be placed at the position 0 and the slit dimension was adjusted for $5.00 \times 0.45 \mathrm{~mm}$. The chromatograms were scanned by a densitometer at $254 \mathrm{~nm}$ and $366 \mathrm{~nm}$ in densitometry TLC Scanner 3. The $R_{f}$ values and fingerprint data were recorded by WINCATS software (Shivatare et al., 2013).

\subsubsection{In vitro inhibition of $\beta$-hematin formation assay}

Briefly, varying concentrations of the extracts from 0 to $2 \mathrm{mg} / \mathrm{ml}$ in Dimethyl sulfoxide (DMSO) were taken in clean Eppendorf's tube then incubated with $3 \mathrm{mM}$ of hematin (freshly dissolved in $0.1 \mathrm{M}$ $\mathrm{NaOH}), 10 \mathrm{mM}$ oleic acid and $1 \mathrm{M} \mathrm{HCl}$. The volume was adjusted to $1 \mathrm{ml}$ using sodium acetate buffer at $\mathrm{pH}$ 5. Chloroquine diphosphate was used as a positive control. The reaction mixtures were incubated overnight at $37^{\circ} \mathrm{C}$ with frequent shaking and then centrifuged (14000 $\mathrm{rpm}, 10 \mathrm{~min}$, at $21^{\circ} \mathrm{C}$ ) and the hemozoin pellet was repeatedly washed with incubation $\left(15 \mathrm{~min}\right.$ at $\left.37^{\circ} \mathrm{C}\right)$ with regular shaking in $2.5 \%(\mathrm{w} / \mathrm{v})$ sodium dodecyl sulphate in phosphate-buffered saline followed by a final wash in $0.1 \mathrm{M}$ sodium bicarbonate until the supernatant was clear (usually 3-8 washes). Finally, the supernatant was removed by washing and then the pellets were dissolved in $1 \mathrm{ml}$ of $0.1 \mathrm{M} \mathrm{NaOH}$ before determining the hemozoin content by measuring the absorbance at $400 \mathrm{~nm}$ (Mojarrab et al., 2014; Asnaashari et al., 2015; Afshar et al., 2018). The percentage inhibition (I\%) of heme crystallization were recorded and then compared to the positive control, using the following equation:

$$
\mathrm{I} \%=[(\mathrm{AN}-\mathrm{AS}) / \mathrm{AN}] \times 100
$$

where,

AN: absorbance of negative control;

AS: absorbance of the test sample.

\subsubsection{Isolation of compound responsible for antimalarial} activity

Based on the higher activity against malaria, the particular extract was further subjected to column chromatography on silica gel (\#60-120 mesh). $5 \mathrm{~g}$ of ethyl acetate fraction was dissolved in $5 \mathrm{ml}$ of ethyl acetate and then mixed with 10 gm of silica gel (\#60-120) in the ratio 1:2 (a drug to silica gel) and air-dried at room temperature. To a column of $500 \mathrm{ml}$ capacity packed with silica gel, $15 \mathrm{~g}$ of silica gel drug mixed material was charged and eluted with hexane (100) [FR 1], hexane: ethyl acetate (80:20) [FR 2], hexane: ethyl acetate (60:40) [FR 3], hexane: ethyl acetate (40:60) [FR 4], hexane: ethyl acetate $(20: 80)$ [FR 5], ethyl acetate (100) [FR 6]. The fractions were collected and concentrated over a hot plate. The concentrated fractions were evaluated for in vitro antimalarial activity by inhibition of $\beta$-hematin formation assay. FR 3 shown maximum activity therefore it was subjected to preparative TLC using mobile phase chloroform: methanol (7:3), which show two spots with Rf value 0.35 and 0.41 . The spots were scooped and subjected to antimalarial activity. The isolated compound was characterized by UV, IR, H-NMR, and mass spectroscopy.

\subsubsection{Correlation study}

Percentage inhibition by the extract was correlated with the percentage yield of the extract and the result was recorded. 


\section{Statistical analysis}

Data are expressed as Mean \pm SEM of triplicates. The concentration showing a higher percentage of inhibition was subjected to statistical analysis with one-way ANOVA, i.e., Dunnett's multiple comparison test to determine the significance of the experimental results.

\section{Results}

3.1 Extraction and percentage yield of the extract

Various solvents, viz., pet-ether, chloroform, ethyl acetate, ethanol, methanol, and water were used for CG flower extraction and resulted in higher yield (25.3\%) in ethyl acetate solvent (Figure 1) and further pharmacognostic screening through chemical tests were performed and the result was shown in Table 1.

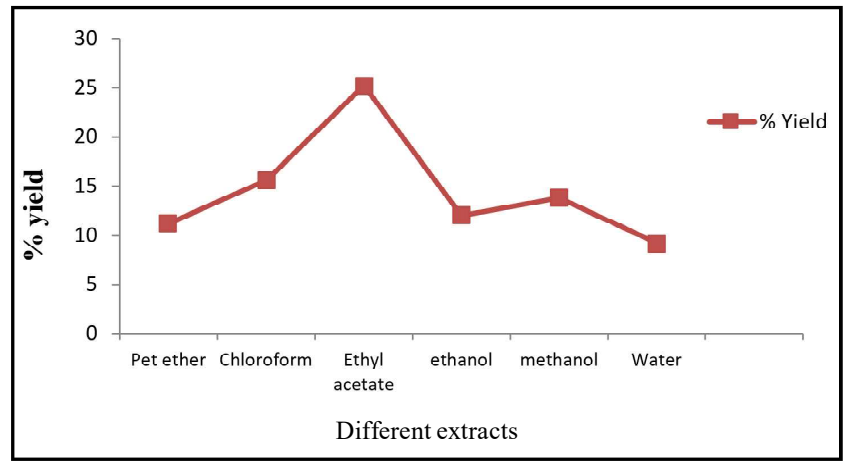

Figure 1: Percentage yield of extract in various solvent.

Table 1: Phytochemical analysis of CG flower extracts

\begin{tabular}{|c|c|c|c|c|c|c|c|}
\hline Phytoconstituents & Various tests & P E E & CE & E A E & $\mathbf{E} \mathbf{E}$ & ME & A E \\
\hline \multirow[t]{4}{*}{ Alkaloids } & Mayer's Test & - & + & - & + & + & - \\
\hline & Dragendroff's Test & - & + & + & - & + & - \\
\hline & Wagner'sTest & - & + & - & - & + & - \\
\hline & Hager's Test & - & + & + & - & - & - \\
\hline \multirow[t]{3}{*}{ Flavonoids } & Shinado Test & - & - & ++ & - & - & + \\
\hline & $\mathrm{FeCl}_{3}$ Test & - & - & + & - & - & + \\
\hline & Lead acetate test & - & - & + & - & - & - \\
\hline Glycoside & Keller killiani Test & - & - & ++ & - & - & + \\
\hline \multirow[t]{2}{*}{ steroids } & Salkowski Test & - & - & ++ & + & + & + \\
\hline & Liebermann-Burchard Test & - & + & ++ & - & + & - \\
\hline \multirow[t]{2}{*}{ Tannins } & $\mathrm{FeCl}_{3}$ Test & - & + & ++ & - & + & + \\
\hline & GelatinTest & - & + & ++ & + & + & + \\
\hline Phenols & FC reagent Test & - & ++ & ++ & - & + & + \\
\hline Proteins & Biuret Test & + & - & - & - & - & - \\
\hline Saponins & Foam Test & - & + & + & - & - & + \\
\hline \multirow[t]{2}{*}{ Triterpenes } & Salkowski Test & - & + & ++ & - & - & + \\
\hline & Liebermann-Burchard Test & - & + & ++ & - & + & + \\
\hline
\end{tabular}

- $\mathrm{PEE}=$ Pet ether extract; $\mathrm{CE}=$ Chloroform extract; $\mathrm{EAE}=\mathrm{Ethyl}$ acetate extract; $\mathrm{EE}=$ Ethanol extract; $\mathrm{ME}=\mathrm{Methanol}$ extract; $\mathrm{AE}=\mathrm{Aqueous}$ extract

\subsection{HPTLC analysis}

Based on the chemical test report, further study was carried out using HPTLC for five different extracts except for pet ether extract.

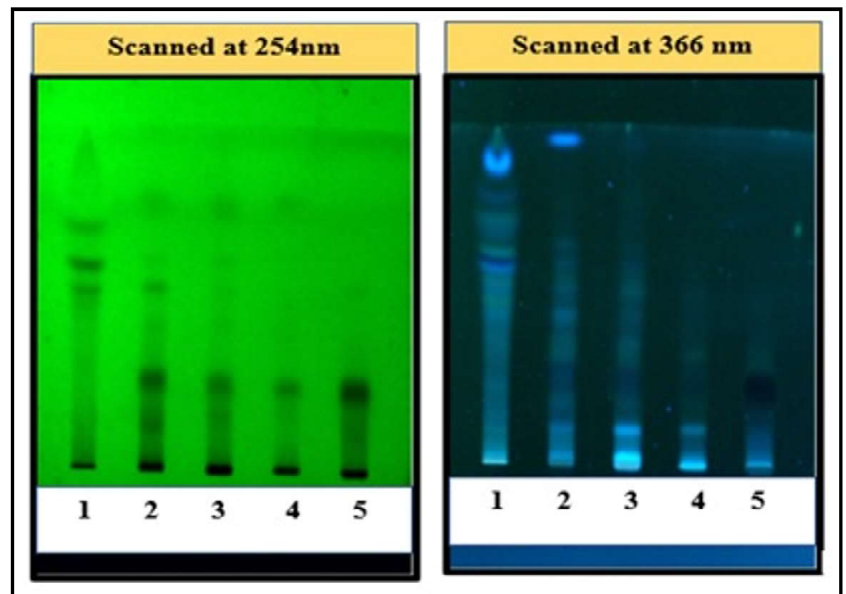

Figure 2: TLC plates scanned at 254 and $366 \mathrm{~nm}$ for C. guianensis flower extracts Tracks: 1-chloroform extract, 2-ethyl acetate extract, 3-ethanol extract, 4-methanol extract, 5-water extract.
The number of solvent systems were tried for CG flower extracts, but the satisfactory resolution was obtained in the solvent system Toluene: Ethyl acetate: Formic acid: Methanol (5.5:3:1:0.5) for flower extracts. HPTLC chromatogram of different extracts of CG flower at 254 and $366 \mathrm{~nm}$ showed in Figure 2 and 3D chromatogram of the extracts showed in Figure 3.

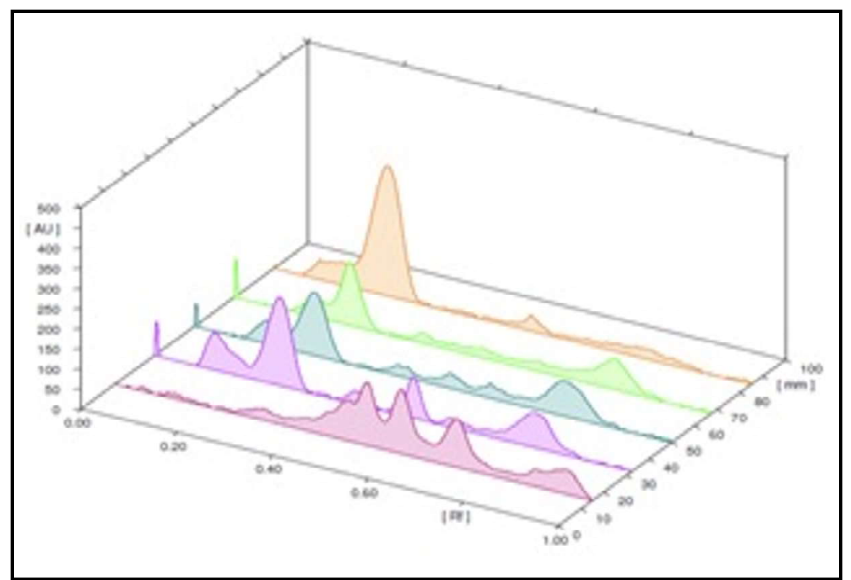

Figure 3: 3D chromatogram of various extracts of CG flowers. 


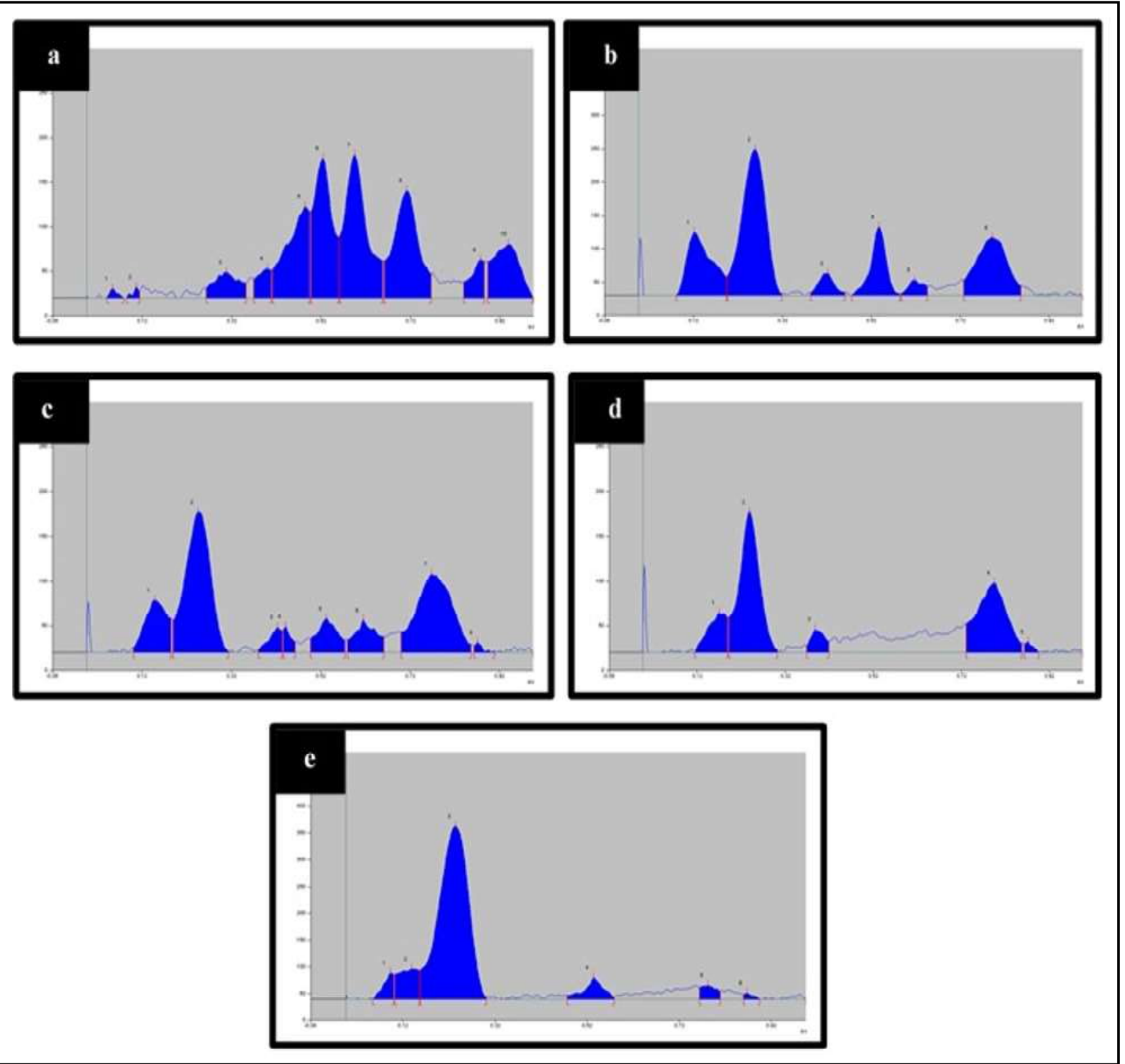

Figure 4: HPTLC chromatogram for various solvent systems of C. guianensis flowers; a-chloroform extract, b-ethyl acetate extract, c-ethanol extract, d-methanol extract, e-water extract.

Rf of different extracts of CG flower showed in Table 2.

Table 2: Rf values of various extracts of CG flowers

\begin{tabular}{|l|l|l|l|}
\hline Sample & Solvent system & No. of peaks & Rf values \\
\hline Chloroform extract & & 10 & $0.06,0.11,0.31,0.40,0.49,0.53,0.60,0.72,0.88,0.94$ \\
Ethyl acetate extract & Toluene: Ethyl acetate: & 6 & $0.13,0.26,0.43,0.54,0.62,0.80$ \\
Ethanol extract & Formic acid: & 8 & $0.15,0.25,0.43,0.45 .0 .54,0.62,0.77,0.88$ \\
Methanol extract & Methanol $(5.5: 3: 1: 0.5)$ & 5 & $0.17,0.24,0.39,0.80,0.88$ \\
Water extract & & 6 & $0.1,0.14,0.24,0.54,0.79,0.87$ \\
\hline
\end{tabular}

\subsection{Antimalarial activity}

All the extracts of CG flowers were screened for anti-malarial activity by inhibition of beta hematin formation assay as per the procedure mentioned in methodology. Ethyl acetate and chloroform extract of CG flowers showed activity during in vitro inhibition of $\beta$-hematin formation assay (Table 3). 
Table 3: Percentage inhibition of beta hematin formation of various extracts of CG

\begin{tabular}{|l|c|c|c|c|c|}
\hline Sa mple & $\mathbf{0 . 2 5} \mathbf{~ m g / m l}$ & $\mathbf{0 . 5} \mathbf{~ m g} / \mathbf{m l}$ & $\mathbf{1 . 0} \mathbf{~ m g} / \mathbf{m l}$ & $\mathbf{1 . 5} \mathbf{~ m g} / \mathbf{m l}$ & $\mathbf{2 . 0} \mathbf{~ m g} / \mathbf{m l}$ \\
\hline Chloroform extract & $7.20 \pm 0.12$ & $13.66 \pm 0.26$ & $26.00 \pm 0.59$ & $36.60 \pm 1.05$ & $47.13 \pm 0.35$ \\
\hline Ethyl acetate extract & $13.8 \pm 0.32$ & $24.7 \pm 0.75$ & $43.4 \pm 0.75$ & $64.43 \pm 0.67$ & $77.27 \pm 0.27$ \\
\hline Ethanol extract & - & - & - & - & - \\
\hline Methanol extract & - & - & - & - & - \\
\hline Water extract & - & - & - & - & - \\
\hline Chloroquine & \multicolumn{5}{|c|}{$74.97 \pm 0.24(0.2 \mathrm{mg} / \mathrm{ml})$} \\
\hline
\end{tabular}

The samples were tested in various concentrations, activity increases as the increase in concentration for ethyl acetate and chloroform extract of CG flowers and results of concentration showing a higher percentage of inhibition (77.27\%) (were subjected to statistical analysis with one-way ANOVA, i.e., Dunnett's multiple comparison test to determine the significance of the experimental results.

Table 4: One-way ANOVA followed by Dunnett's test for antimalarial

\begin{tabular}{|l|l|c|l|}
\hline SI. No. & Sample & Concentration & Percentage inhibition \\
\hline 1 & Chloroform extract of flowers & $2 \mathrm{mg} / \mathrm{ml}$ & $47.13 \pm 0.35^{* *}$ \\
2 & Ethyl acetate extract of flowers & $2 \mathrm{mg} / \mathrm{ml}$ & $77.27 \pm 0.27^{* * *}$ \\
3 & StandardChloroquine diphosphate & $0.2 \mathrm{mg} / \mathrm{ml}$ & $74.97 \pm 0.24$ \\
\hline
\end{tabular}

- Values are expressed as Mean $\pm \operatorname{SEM}(\mathrm{n}=3)$ and $\mathrm{P}^{* *}<0.01$, and $\mathrm{P}^{* * *}<0.001$, significant.

\subsection{Isolation of compound}

Ethyl acetate extract of CG flowers showed the maximum activity, therefore, this extract was subjected for column chromatography eluting with mobile phase Hexane (100) [FR 1], Hexane: Ethyl acetate (80:20) [FR 2], Hexane: Ethyl acetate (60:40) [FR 3], Hexane: Ethyl acetate (40:60) [FR 4], Hexane: Ethyl acetate (20:80) [FR 5], Ethyl acetate (100) [FR 6]. All six fractions were collected from the Column. The fractions were concentrated and dried under vacuum and evaluated for in vitro antimalarial activity by inhibition of $\beta$-hematin formation assay. FR 2 showed $36.58 \%$ inhibition whereas FR 3 shown \% inhibition of $79.23 \%$. FR 3 was further purified by preparative TLC using mobile phase chloroform: methanol $(7: 3)$ which shown 2 spots of $R f$ value of 0.35 and 0.41 . The spots were scooped and evaluated for antimalarial activity. The compound of Rf value 0.41 shown maximum activity $67.23 \%$ and it was characterized.

The isolated compound was identified by UV spectrophotometer where $\lambda$ max showed at $257 \mathrm{~nm}$ and the presence of conjugation as well as chromophore. Further, FTIR, H-NMR, and MASS spectroscopy analysis revealed the isolated compound was Stigmasterol (Figure 5, 6, 7 and 8).

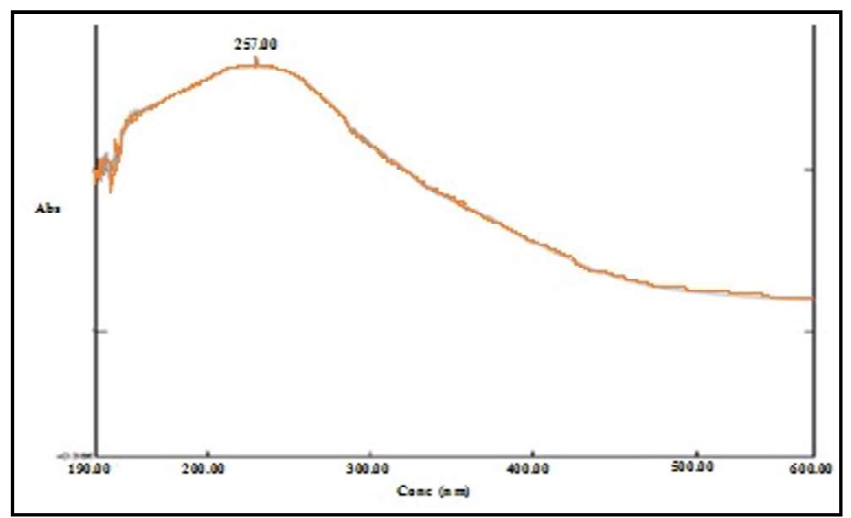

Figure 5: UV absorbance of isolated compound.

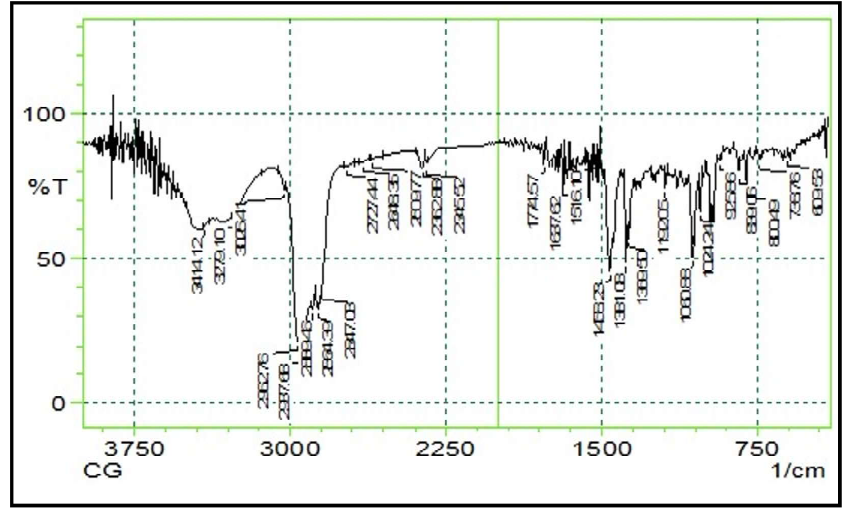

Figure 6: FTIR spectra of isolated compound.

FTIR graph showed the characteristic absorption band were exhibited at $3414.12 \mathrm{~cm}^{-1}$ (OH group), $2924.18 \mathrm{~cm}^{-1}$ (C-H stretching), $2852.81 \mathrm{~cm}^{-1}$ (C-H stretching), $1458.23 \mathrm{~cm}^{-1}$ (C-H bend), $1637.62 \mathrm{~cm}^{-1}$ $(\mathrm{C}=\mathrm{C}) 1192.05 \mathrm{~cm}^{-1}$ (OH bending), $1060.88 \mathrm{~cm}^{-1} \mathrm{C}-\mathrm{C}$ stretching), $738.76 \mathrm{~cm}^{-1}\left(\mathrm{CH}_{2}\right.$ rocking).

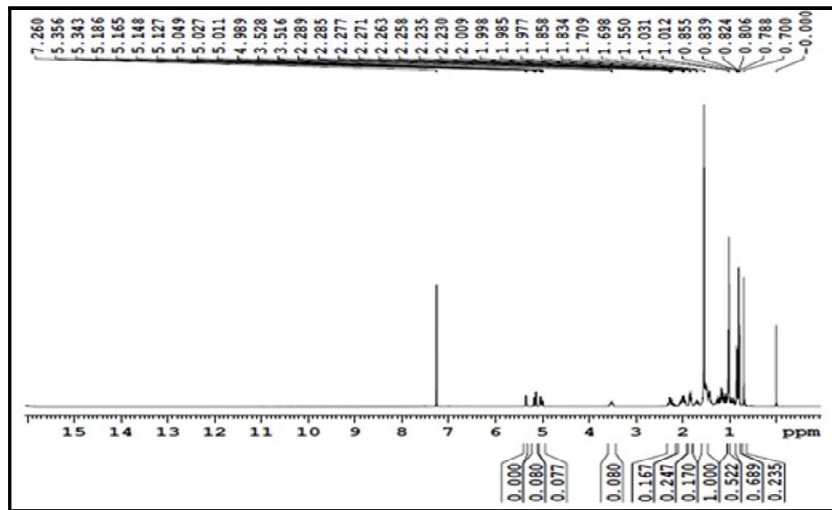

Figure 7: ${ }^{1} \mathrm{H}-\mathrm{NMR}$ spectra of isolated compound. 
Proton NMR data revealed isolated compound has $\mathrm{CH}_{3}$ group with chemical shift $\delta 0.700, \mathrm{CH}_{2}$ group was identified with chemical shift $\delta 0.788-0.855, \mathrm{CH}=\mathrm{CH}$ group with chemical shift $\delta 1.550$ and OH group with chemical shift $\delta 3.489-3.556$.
Finally, the MS screening and confirmation of isolated compound was detected by their molecular ions at $\mathrm{m} / \mathrm{z} 412$ which correspond to the molecular mass of Stigmasterol $412.69 \mathrm{~g} / \mathrm{ml}$.

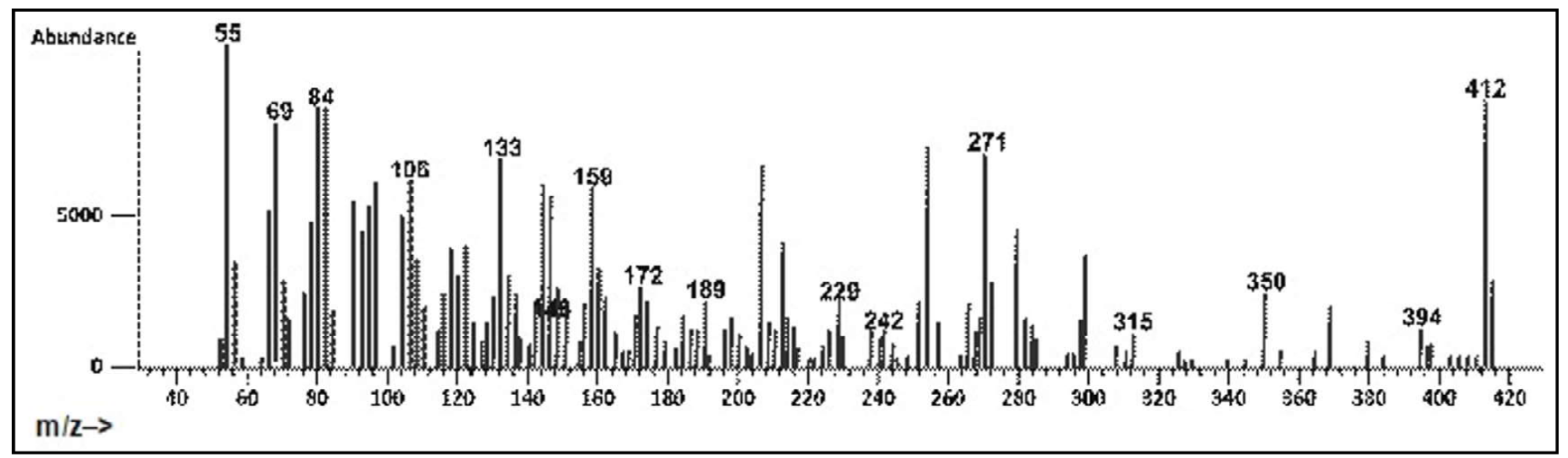

Figure 8: Mass spectra of isolated compound.

All the above data was compared to the values from literature and it is clearly suggested that isolated compound have structure of Stigmasterol (Figure 9).

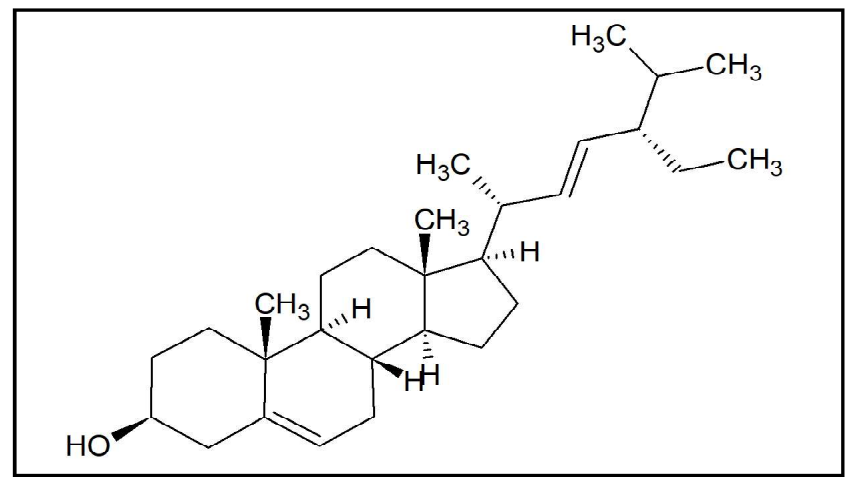

Figure 9: Stigmasterol.

\subsection{Correlation study}

Based on the activity, ethyl acetate flower extract of CG was correlated with the inhibition of the $\beta$-hematin formation and recorded significant positive regration effect with the percentage yield (Figure 10), with the $\mathrm{R}^{2}=0.991$.

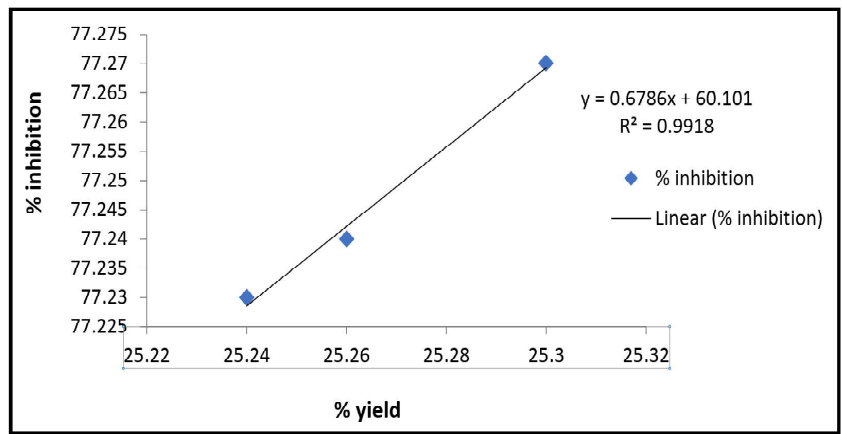

Figure 10: Correlation study of $\%$ yield and $\%$ inhibition of ethyl acetate extract of CG flower.

\section{Discussion}

The Plasmodium parasite, degrades haemoglobin $(\mathrm{Hb})$ within the infected erythrocytes to use the catabolic products as the source of nutrition for its growth and proliferation. Further, free $\mathrm{Hb}$ is released as a toxic byproduct in this process that affects the cellular metabolism with the mechanism of membrane peroxidation and thereafter, inhibits a variety of enzymes. Hence, the malaria parasite uses several detoxification pathways to get rid of excess heme. Polymerisation of heme into an insoluble, nontoxic crystalline compound, hemozoin (also called malaria pigment) is believed to be prominent way of detoxification. Therefore, the inhibition of hemozoin formation is an attractive target towards development of antimalarial drugs such as 4-aminoquinolines and also considered as suitable target for drug screening methods. Various in vitro assays based on spectral characteristics and different solubility of monomeric heme and $\beta$-hematin (synthetic analogue of hemozoin) have been used for screening of natural antimalarial as well as novel synthetic compounds.

In the present study the percentage yield of all the extracts was calculated and showed higher yield with ethyl acetate extract followed by chloroform extract of CG flower. The presence of various phytoconstituents were more in ethyl acetate extract of CG flower especially sterols which is responsible for antimalarial activity. An earlier report also revealed the same where ethyl acetate extract showed the presence of sterols and flavonoids (Younes et al., 2018). Thereafter, dose dependent antimalarial activity showed with the ethyl acetate and chloroform extracts which were also correlated with the earlier report (Nardos and Makonnen, 2017; Herraiz et al., 2019). In the literature, it was revealed that due to the presence of sterols, alkaloids and flavonoids in the plant body, they show antimalarial activity (Kohler et al., 2002; Chander et al., 2016; Meesala et al., 2017; Laryea and Borquaye, 2019) which was similar with our findings where ethyl acetate flower extract showed the presence of sterols, especially Stigmasterol and confirmed with the antimalarial activity. 


\section{Conclusion}

Among various extracts of CG flowers, ethyl acetate extract showed the potent anti-malarial activity in $\beta$-hematin formation assay. Further isolation of the compound that is responsible for the activity was carried out and characterized to determine the structure of the compound and the compound was found to be Stigmasterol.

\section{Conflict of interest}

The authors declare that there are no conflicts of interest in the course of conducting the research. All the authors had final decision regarding the manuscript and decision to submit the findings for publication.

\section{References}

Afshar, F.H.; Delazar, A.; Asnaashari, S.; Vaez, H.; Zolali, E. and Asgharian, P. (2018). Screening of antimalarial activity of different extracts obtained from three species of Scrophularia growing in Iran. Iranian Journal of Pharmaceutical Research, 17(2):668-676.

Aravind, D.S.; Karthikeyan, R. and Babu, P.S. (2017). In vitro antitubercular activity of flowers of Couroupita guianensis. Journal of Applied Pharmaceutical Research, 5(1):27-29.

Asnaashari, S.; Afshar, F.H.; Ebrahimi, A.; Moghadam, S.B. and Delazar, A. (2015). In vitro antimalarial activity of different extracts of Eremastachys macrophylla Montbr and Auch. Bioimpacts, 5(3):135-140.

Bhagyasri, T.; Sunitha, B. and Guntuku, G. (2014). In vitro cytotoxic and antibacterial activity of various flower extracts of Couroupita guianensis. International Journal of Pharmacognosy and Phytochemical Research, 6(1):113-117.

Chander, M.P.; Pillai, C.R.; Sunish, I.P. and Vijayachari, P. (2016). Antimicrobial and antimalarial properties of medicinal plants used by the indigenous tribes of Andaman and Nicobar Islands, India. Microb. Pathog., 96:85-88.

Chavda, V. (2015). Cannonball tree: The alchemist plant. Innoriginal International Journal of Sciences, 2(5):6-9.

Eknat, A. A. and Shivchandraji, L. K. (2002). Amirin palmitate isolation from Couroupita guianensis Aubl. leaves. Indian Drugs, 39:213-216.

Elumalai, A.; Naresh, V.; Eswaraiah, M.C.; Narendar, P. and Kumar, R. (2012). Evaluation of antiulcer activity of Couroupita guianensis Aubl leaves. Asian Journal of Pharmacy and Technology, 2(2):64-66.

Geetha, M.; Shankar, M.B.; Mehta, R.S. and Saluja, A.K. (2005). Antifertility activity of Artabotrys odoratissimus Roxb Tissimus Roxb and Couroupit guianensis Aubl. Journal of Nat. Remed., 5(2):121-125.

Gousia, S.K.; Kumar, K.A.; Kumar, T.V. and Latha, J.N. (2013). Biological activities and medicinal properties of Couroupita guianensis. International Journal of Pharmacy and Pharmaceutical Science Research, 3(4):140-143.

Herraiz, T.; Guillén, H.; González-Peña, D. and Aran, V.J. (2019). Antimalarial quinoline drugs inhibit $\beta$-hematin and increase free hemin catalyzing peroxidative reactions and inhibition of cysteine proteases. Sci. Rep., 9:15398. https://doi.org/10.1038/s41598-019-51604-z.

Jasmine, F.S. and Moorthi, V.P. (2017). Couroupita guianensis: The reservoir of medicinal compounds of human welfare. Asian Journal of Pharmaceutical and Clinical Research, 10(3):50-52.
Kaushik, N. K.; Bagavan, A.; Rahuman, A. A.; Zahir, A. A.; Kamaraj, C.; Elango, G.; Jayaseelan, C.; Kirthi, A. V.; Santhoshkumar, T.; Marimuthu, S.; Rajakumar, G.; Tiwari, S. K. and Sahal, D. (2015). Evaluation of antiplasmodial activity of medicinal plants from North Indian Buchpora and South Indian Eastern Ghats. Malaria Journal, 14:65. https://doi.org/10.1186/s12936-015-0564-z.

Kohler, I.; Kirstina, J.S.; Karsten S.; Marco, A.H.; Ricardo, A.I.; Walter, G. B.; Ulrich, B. and Eckart, E. (2002). In vitro antiplasmodial investigation of medicinal plants from El Salvador. Z Naturforsch., 57(3-4): 277-281.

Laryea, M.K. and Borquaye, L.S. (2019). Antimalarial efficacy and toxicological assessment of extracts of some ghanaian medicinal plants. Journal of Parasitology Research, pp:1-9. Article ID 1630405, 9 pages https://doi.org/10.1155/2019/1630405.

Lawrence, A.S. and Venkatraman, A. (2020). An updated review on Couroupita guianensis Aubl: A sacred plant of India with myriad medicinal properties. J. Herbmed. Pharmacol., 9(1):1-11.

Manimegalai, S.; Sridharan, T.B.; Rameshpathy, M. and Rajeswari, D.V. (2014). Antioxidant, phytochemical screening and antimicrobial activity of Couroupita guianensis flower extract. Der. Pharmacia. Lettre., 6(6):251-256.

Meesala, S.; Gurung, P.; Karmodiya, K. ; Parameswaran, P.S. and Watve, M. (2017). Isolation and structure elucidation of halymeniaol, a new antimalarial sterol derivative from the red alga Halymenia floresii. Journal of Asian Natural Products Research, 20:1-8.

Mojarrab, M.; Shiravand, A.; Delazar, A. and Afshar, F.H. (2014). Evaluation of in vitro antimalarial activity of different extracts of Artemisia aucheri and $A$. armeniaca Lam. and fractions of the most potent extracts. The Scientific World Journal, pp:1-6. Article ID 825370. https://doi.org/10.1155/2014/825370.

Nardos, A. and Makonnen, E. (2017). In vivo antiplasmodial activity and toxicological assessment of hydroethanolic crude extract of Ajuga remota. Malar J., 16:25. https://doi.org/10.1186/s12936-017-1677-3.

Prabhu, V. and Ravi, S. (2017). Isolation of phytoconstituents from the flowers of Couroupita guianensis. Indian J. Chem., 56:709-713.

Pradhan, D.; Panda, P.K. and Tripathy, G. (2008). Evaluation of the immunomodulatory activity of the methanolic extract of Couroupita guianensis Aubl flowers in rats. Nat. Prod. Rad., 8(1):37-42.

Ramadoss, K. (2017). In vitro anti tubercular activity of flowers of Couroupita guianensis L. Journal of Applied Pharmaceutical Research, 5(1):27-29.

Ramalakshmi, C.; Ranjitsingh, A.J.; Kalirajan, K.; Kalirajan, A.; Athinarayanan, G. and Mariselvam, R. (2013). A preliminary screening of the medicinal plant Couroupita guianensis for its antimicrobial potential against clinical and fish-borne pathogens. Elixir. Appl. Biol., 57:14055-14057.

Ramalakshmi, C.; Kalirajan, A.; Ranjitsingh, A.J. and Kalirajan, K. (2014). Bioprospecting of medicinal plant Couroupita guianensis for its potential anti-ulcer activity. Int. J. Applied Biol. Pharm. Technol., 5:226-232.

Rane, J.B.; Vahanwala, S.J.; Golatkar, S.G.; Ambaye, R.Y. and Khadse, B.G. (2001). Chemical examination of the flowers of Couroupita guianensis Aubl. Indian J. Pharm. Sci., 63:72-73.

Regina, V. (2014). Pharmacognostical studies of various parts of Couroupita guianensisaubl. Int. J. Curr. Res. Biosci. Plant Biol., 1:17-26.

Sathishkumar, G.; Jha, P.K.; Vignesh, V.; Raikuberan, C.; Jevraj, M.; Selvakumar, M.; Jha, R. and Sivaramakrishnan, S. (2016). Cannonball fruit (Couroupita guianensis) extract mediated synthesis of gold nanoparticles and evaluation of its antioxidant activity. Journal of Molecular Liquids, 215:229-236. 
Shah, G.N.; Shete, S.A.; Patil, V.S.; Patil, K.D. and Killedar, S.G. (2012). Standardization and anti bacterial activity of Couroupita guianensis fruitpulp extract. International Journal of Pharmacognosy and Phytochemical Research, 4:85-89.

Shivatare, R.S.; Nagore, D.H. and Nipanikar, S.U. (2013). HPTLC an important tool in standardization of herbal medical product: A review. Journal of Scientific and Innovative Research, 2(6):1086-1096.

Sumathi, S. and Anuradha, R. (2017). Couroupita guianensis aubl: An updated review of its phytochemistry and pharmacology. Asian Journal of Pharmacy and Pharmacology, 3(1):1-8.

Sundararajan, R. and Koduru, R. (2014). A complete profile on Couroupita guianensis-traditional uses, pharmacological activities and phytoconstituents. Pharmacoph. Ore., 5(1):147-159.
Umachigi, S.P.; Jayaveera, K.N.; Ashok kumar, C.K. and Kumar, G.S. (2007). Antimicrobial, wound healing, and antioxidant potential of Couroupita guianensis in rats. Pharmacol., 3:269-281.

WHO. (2010). The African health monitor: African traditional medicine day. Geneva: World Health Organization.

WHO. (2019). World malaria report: 2019. Geneva: World Health Organization.

Younes, A.B.; Salem,M.B.; Abed, H.E and Jarraya, R. (2018). Phytochemical screening and antidiabetic, antihyperlipidemic, and antioxidant properties of Anthyllis henoniana (Coss.) Flowers extracts in an Alloxan-induced Rats Model of Diabetes. Evidence-Based Complementary and Alternative Medicine, pp:1-14. Article ID 8516302. https://doi.org/10.1155/2018/8516302.

Citation: R. Shwetha, T. S. Roopashree, Kuntal Das, N. Prashanth and Rakesh Kumar (2020). HPTLC fingerprinting of various extracts of Couroupita guianensis flowers for establishment of in vitro antimalarial activity through isolated compound. Ann. Phytomed., 9(1):133-140. http://dx.doi.org/10.21276/ap.2020.9.1.17 